Research Article

\title{
Synthesis of Solid Acid Catalyst from Fly Ash for Eugenol Esterification
}

\author{
Nur Hidayati*, Titik Pujiati, Elfrida B. Prihandini, Herry Purnama \\ Chemical Engineering Department, Universitas Muhammadiyah Surakarta, Jl. A. Yani Tromol Pos, \\ Pabelan, Kartasura, Surakarta 57102, Indonesia
}

Received: $25^{\text {th }}$ January 2019; Revised: $12^{\text {th }}$ May 2019; Accepted: $20^{\text {th }}$ May 2019; Available online: 30 ${ }^{\text {th }}$ September 2019; Published regularly: December 2019

\begin{abstract}
A series of fly ash-based heterogeneous acid catalysts were prepared by chemical and thermal treatment. Fly ash was chemically activated using sulfuric acid and followed by thermal activation. Characterization methods of XRD, BET, SEM-EDX, and the performance in esterification of eugenyl acetate production was carried out to reveal the physical and chemical characteristics of prepared catalysts. Activated catalyst showed high silica content (96.5\%) and high BET surface area of $70 \mathrm{~m}^{2} . \mathrm{g}^{-1}$. The catalyst was proven to be highly active solid acid catalyst for liquid phase esterification of eugenol with acetic acid yielding eugenyl acetate. A yield of $43-48 \%$ was obtained with activated fly ash catalysts for 90 minutes reaction. These catalysts may replace beneficially the conventional homogenous liquid acid to the eco-friendly heterogeneous one. Copyright (C) 2019 BCREC Group. All rights reserved
\end{abstract}

Abstract

Keywords: fly ash; solid acid catalyst; esterification; eugenyl acetate.

How to Cite: Hidayati, N., Pujiati, T., Prihandini, E.B., Purnama, H. (2019). Synthesis of Solid Acid Catalyst from Fly Ash for Eugenol Esterification. Bulletin of Chemical Reaction Engineering \& Catalysis, 14(3): 683-688 (doi:10.9767/bcrec.14.3.4254.683-688)

Permalink/DOI: https://doi.org/10.9767/bcrec.14.3.4254.683-688

\section{Introduction}

Coal fly ash is an inorganic deposit and waste product arising from the coal combustion processes in coal-fired power station or steam production. Bulky quantities of coal fly ash are kept in the form of waste deposits which contaminate the environment as inorganic pollution and cause deleterious effects on human health. Fly ash physically is in the form of fine particles with an average size of less than 20 $\mu \mathrm{m}$ and has low to medium bulk density (0.54$\left.0.86 \mathrm{~g} . \mathrm{cm}^{-3}\right)$, high surface area $300-500 \mathrm{~m}^{2} \mathrm{~kg}^{-1}$ and light texture [1]. The acidity depends on the ratio of alkaline and acid-forming element in the ash but mostly it tends to alkaline [2]. Fly

* Corresponding Author.

Email: nur.hidayati@ums.ac.id (N. Hidayati); herry.purnama@ums.ac.id (H. Purnama) ash has a complex heterogeneous mixture of amorphous and crystalline phases with oxides of $\mathrm{Si}, \mathrm{Al}, \mathrm{Ca}, \mathrm{Mg}$, and $\mathrm{Na}$ as major components [3].

Fly ash has been proven its suitability for applications variety such as admixture in cement/concrete, brick and potential materials for some chemical industries. However, in some countries the utilization of total fly ash produced is very low [4]. The other applications of fly ash is under developed for examples as catalyst and catalyst support for catalytic cracking [5], esterification [6], trans-esterification [7], dehydration [8], oxidation [9, etc.

Esterification reaction are used to produce chemicals such as drugs [10], biodiesel [11], and for food industry [12,13]. Typically, esterification is performed using homogeneous catalysts such $\mathrm{H}_{2} \mathrm{SO}_{4}, \mathrm{H}_{3} \mathrm{PO}_{4}$, and $\mathrm{HF}$ [14]. However these acids are destructive, environmentally harmful and difficult to recover from the reac- 
tion mixture. On-going efforts involve the use of solid acid catalyst: Amberlyst-15 [15], Alalginat [14], and zirconia UDCaT-5 [16], allowing for efficient catalyst separation and recovery and minimizing corrosion effects. Esterification of eugenol to eugenyl ester have been carried out using zirconia UDCaT-5 [16], molecular sieve $4 \AA$ and Amberlite XAD-16 [17], and anion exchange Amberlyst A-21 [18]. High conversion $(90 \%)$ has been achieved for two hours reaction by using Amberlite XAD-16.

Application for fly ash has developed, more importantly in its roles in catalytic oxidation, chlorination, as a synthetic derivative of 2-mercaptobenzothiazole, and as a solid acid catalyst for esterification. Fly ash was activated chemically to increase the composition of silicon up to $80 \%$ and is used to support zirconium sulfate as a catalyst in benzylation reactions. The use of fly ash does not just aid in cutting down catalyst expenses but also to show high acid levels and enlarge the catalytic activities in benzylation reactions from benzene and toluene [19]. The catalyst fly ash- $\mathrm{H}_{2} \mathrm{SO}_{4}$ poses an ability to increase efficiency for synthesizing chalcones by reaction of chalcones aldon-flow condensation [20]. In the present work, sulfonated fly ash catalysts have been prepared with different calcination time and tested their activity for esterification of eugenol present in clove leaf oil.

\section{Materials and Methods}

\subsection{Materials}

Acetic acid (96\% purity) and sulfuric acid (96\% purity) were supplied from Merck. Clove leaf oil was purchased from local market in Boyolali, Indonesia. All the received chemicals were used without any further purification. The fly ash was a solid waste obtained from petrochemical company in Gresik, Indonesia.

\subsection{Catalyst Preparation}

Grey fly ash in the form of powder with a size of 50-110 $\mu \mathrm{m}$ was washed with distilled water. Fifty grams of fly ash was impregnated with $100 \mathrm{ml}$ of sulfuric acid solution for 24 hours. The fly ash was then separated from the solution. The acquired solid was washed several times with distilled water until the $\mathrm{pH}$ was neutral. It was then dried at a temperature of $100{ }^{\circ} \mathrm{C}$ to remove the water content found on the surface. Next, the remaining fly ash was calcinated at $400{ }^{\circ} \mathrm{C}$ for a specific time $(2,4,6$, or 8 hours).

\subsection{Catalyst Characterization}

The surface areas and pore size of the prepared catalysts were determined by using the Brunauer Emmett Teller (BET) method. The data were acquired on Quantachrome NovaWin Analyzer (Quantachrome Instru-

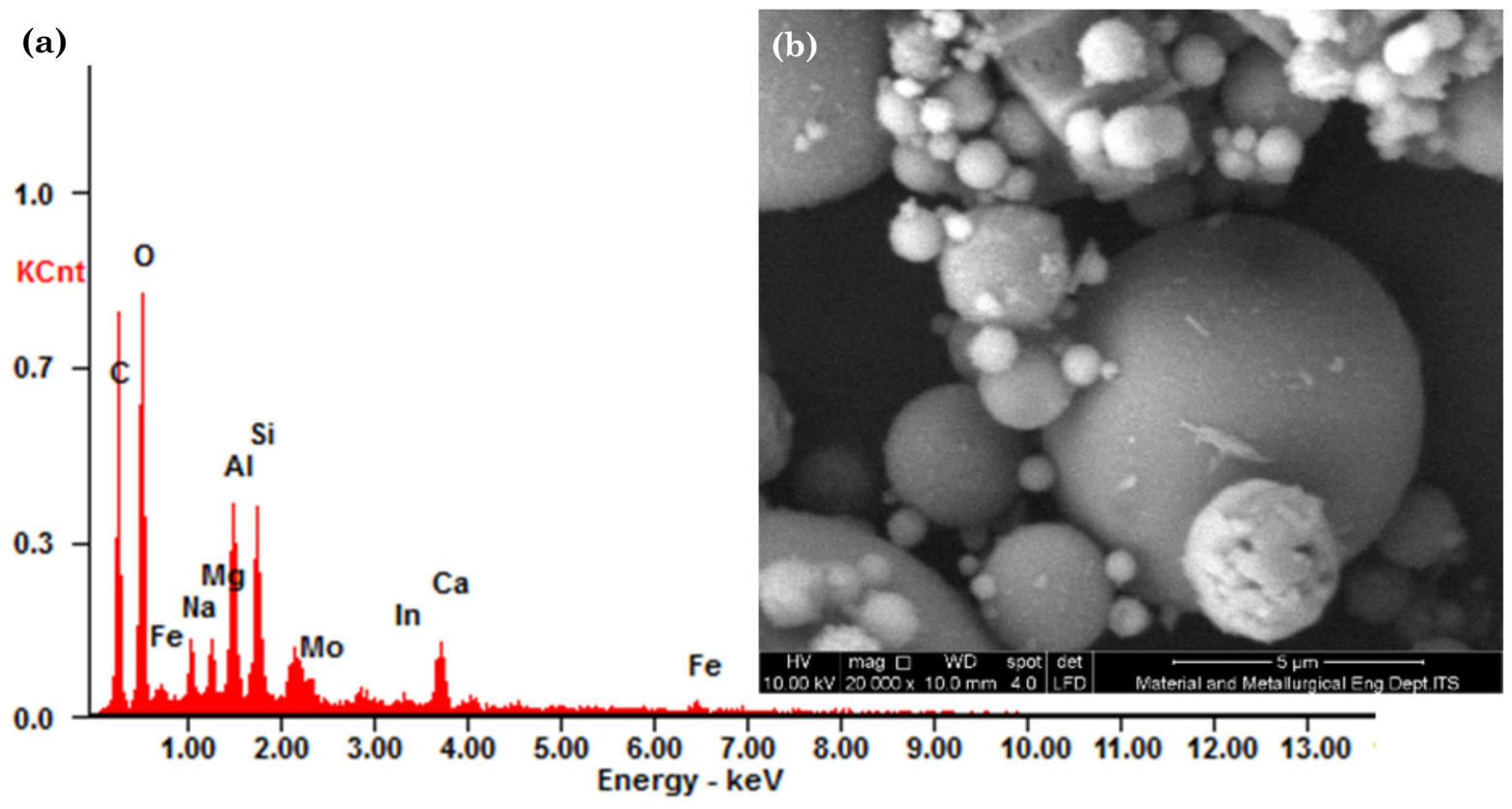

Figure 1. EDAX spectra (a) and SEM images of untreated fly ash (b). 
ments) and nitrogen physical adsorption at liquid nitrogen temperature $-195{ }^{\circ} \mathrm{C}$. XRD analysis was used to determine the shape of structure and the crystallinity of fly ash catalyst. Diffractogram was obtained from the diffractometer Philips XPert MPD at the $2 \theta$ angle ranging from 10 to $90^{\circ}$ and wavelength, $\lambda=$ $0.154 \mathrm{~nm}$. SEM-EDAX observation was performed on FEI Inspect s50 model. The catalytic activity was identified by eugenol conversion to eugenyl acetate. Esterification reactions were carried out without any organic solvent in $500 \mathrm{~mL}$ three-neck glass equipped with a condenser and magnetic stirrer. Reactions were performed at $60{ }^{\circ} \mathrm{C}$ with eugenol to acetic acid of $1: 1$ ratio using $3 \%$ sulfated fly ash for 90 minutes. After the reaction, the catalyst was separated from the liquor and the unreacted acetic acid was titrated using $\mathrm{NaOH}$ solution.

Table 1. BET surface area of fly ash catalyst

\begin{tabular}{cc}
\hline Calcination time $(\mathrm{h})$ & Surface area $\left(\mathrm{m}^{2} \cdot \mathrm{g}^{-1}\right)$ \\
\hline Untreated & 5.08 \\
2 & 70.13 \\
4 & 69.80 \\
6 & 56.31 \\
8 & 49.05 \\
\hline
\end{tabular}

\section{Result and Discussion}

\subsection{SEM-EDAX Analysis}

The morphology of untreated and activated fly ash were examined using scanning electron microanalyzer equipped with energy dispersive X-ray spectroscopy (EDAX) which identifies constituent atoms and approximate amount of atoms. Figures 1 and 2 show the SEM micrograph of original fly ash and activated fly ash, respectively.

The SEM image of surface of untreated fly ash (Figure 1b) was observed to have a smooth surface and wide range in diameter size. The widest diameter is more than $5 \mu \mathrm{m}$. On the other hand, after treating with acid and calcination process, their appearance are slightly rougher (Figure $2 b$ ). Some particles aggregate, but some also shrink to sizes less than $5 \mu \mathrm{m}$. EDAX spectra of raw fly ash represents high percentages of $\mathrm{SiO}_{2}, \mathrm{Al}_{2} \mathrm{O}_{3}$, and $\mathrm{CaO}$ as the major constituents and small amounts of $\mathrm{Fe}_{2} \mathrm{O}_{3}$, $\mathrm{MgO}, \mathrm{Na}_{2} \mathrm{O}, \mathrm{MoO}_{3}$ and $\mathrm{In}_{2} \mathrm{O}_{3}$. Acid treatment and high temperature heating for 4 hours leach out some constituents and therefore increase $\mathrm{SiO}_{2}$ content. The silica composition is doubled from 14 to $31 \%$ wt. Zeng et al. proved that acid activation on fly ash had introduced the more hydroxyl groups (-OH) in the fly ash [8]. Therefore, it may change the acid strength of catalyst. It was reported that SEM analysis on the manufacturing of fly ash sulfonation as a catalyst in the synthesis of free solvents from aryl chalcones that increased silica levels after chemical activation was due to the loss of a

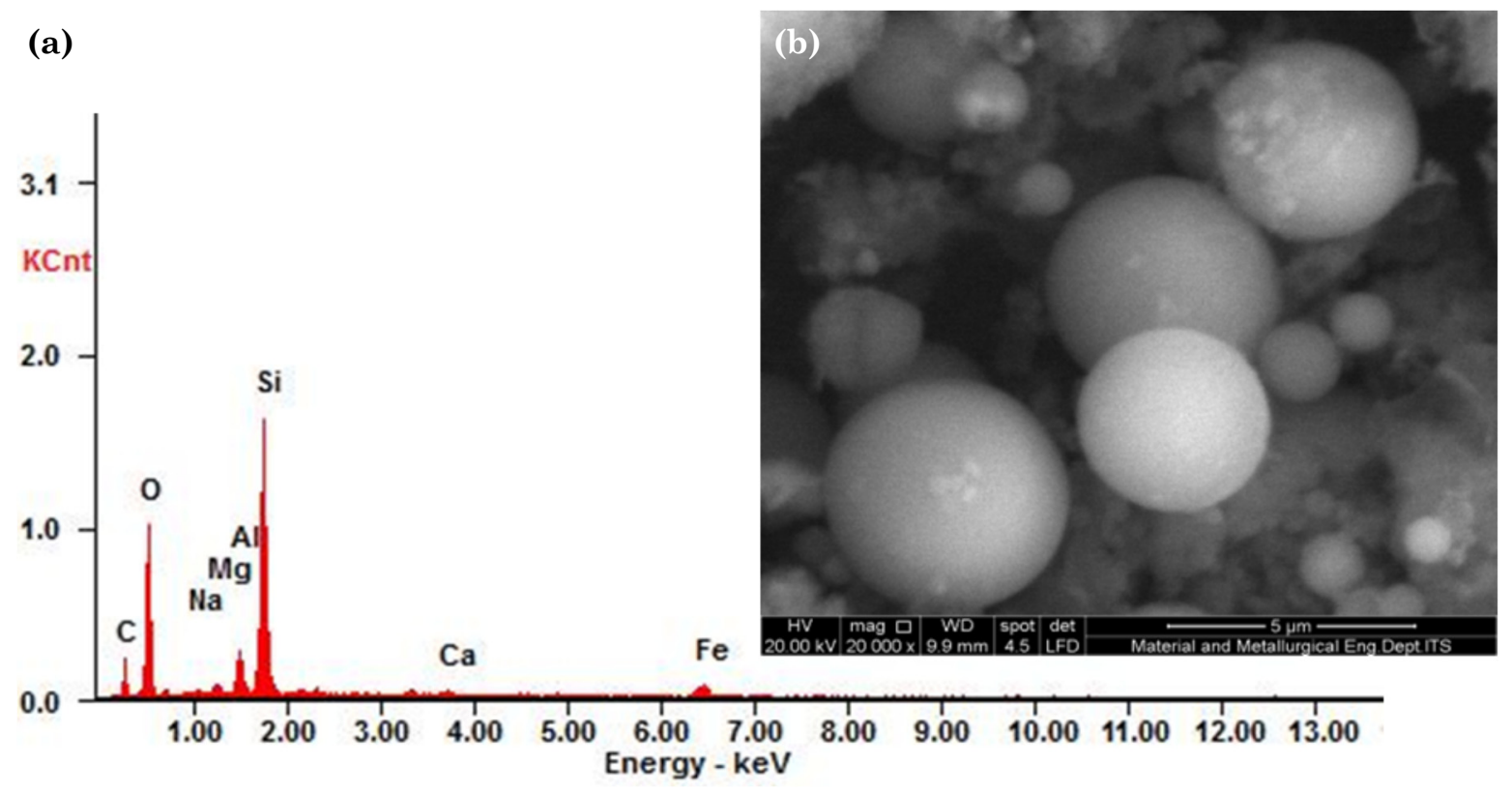

Figure 2. EDAX spectra (a) and SEM images of activated fly ash (b). 
large number of other components during impregnation by $\mathrm{H}_{2} \mathrm{SO}_{4}$ [20]. Apart from that, the surface of the particles has been slightly corroded by $\mathrm{H}_{2} \mathrm{SO}_{4}$.

\subsection{XRD Analysis}

The purpose of XRD analysis is to obtain information about the change of mineral and crystalline structure characteristics from raw materials and products in the course of synthesis process. Figure 3 shows XRD patterns sulfonated fly ash catalysts at different calcination time. Diffractograms of untreated fly ash exhibit typical diffraction peak at $2 \theta$ of $26.60^{\circ}$ and $50.12^{\circ}$. These characteristic peaks show the predominant quartz phase $\left(\mathrm{SiO}_{2}\right)$ with a major peak at $2 \theta$ of $26.60^{\circ}$ and then also identified the less intense phase for $\mathrm{MgO}$ dan $\mathrm{Al}_{6} \mathrm{O}_{18}$. Impregnation and calcination causes the characteristic peak at $2 \theta$ of $20.70-20.90^{\circ}$ and $50.11^{\circ}$ to be clearly identified, which shows the peak of crystalline quartz. Treated fly ash shows that $\mathrm{SiO}_{2}$ quartz is the dominant phase from $60 \%$ up to almost $100 \%$. Mazumder et al. reported that

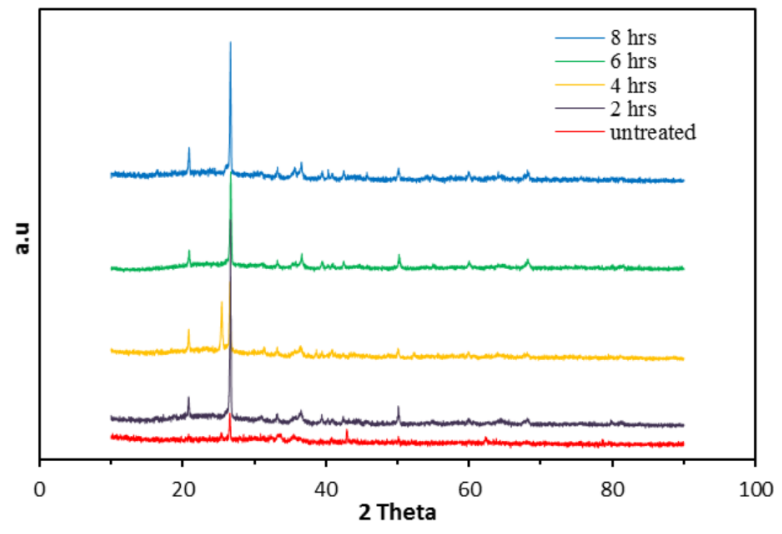

Figure 3. XRD pattern for the effect of calcination time on fly ash formation.

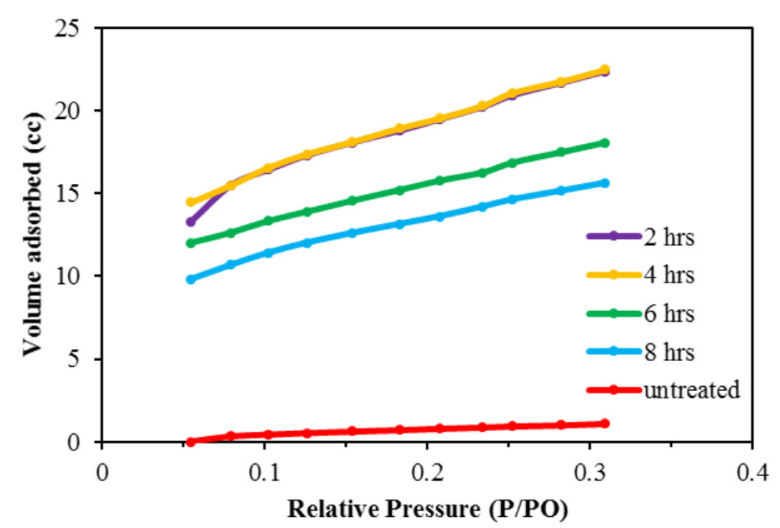

Figure 4. Nitrogen adsorption-desorption isotherm of untreated and treated fly ash. fly ash activated with o-phosphoric acid induce dissolving some of the crystalline component of raw fly ash by acid [6]. Therefore, the crystallinity of fly ash was reduced during acid and heating treatment, consequently the amorphous of fly ash was increased.

\subsection{BET Surface Area}

BET test results are shown in Table 1. Untreated fly ash has a BET surface area of around $5 \mathrm{~m}^{2} / \mathrm{g}$. Impregnation with sulfuric acid and calcination at $400^{\circ} \mathrm{C}$ causes the surface area to multiply by 9-14, ranging from 49.05$70.13 \mathrm{~m}^{2} / \mathrm{g}$. Fortunately, higher surface area of the catalyst may cause more acid for the reaction. The time of calcination can affect the surface area particles. A high duration of calcination can decrease the BET surface area. This shrinking of surface area is caused by the agglomeration process of particles. During calcination, particles may undergo condensation until hydroxyl groups are released, and the binding and rearranging of particles result in a more stable configuration. Other studies reveal the same results, that solid acid fly ash catalyst that were synthesized with o-phosphoric acid and calcinated at a temperature of $300{ }^{\circ} \mathrm{C}$ for 3 hours had an increased surface area from 0.09 to $21.92 \mathrm{~m}^{2} \cdot \mathrm{g}^{-1}[6]$.

The $\mathrm{N}_{2}$ adsorption and desorption isotherms obtained shows that untreated fly ash and two hours treated fly ash form micropores at around $15.53 \AA$ and $16.94 \AA$. Extended calcination time results in mesopores volume, 29.56-49.06 ̊. The textural mesopores are essential because they are able to facilitate reactants transport to catalyst active sites located inside the pores. The nitrogen adsorptiondesorption isotherm is presented in Figure 4. The lower adsorption volume on the untreated fly ash indicates a low surface area.

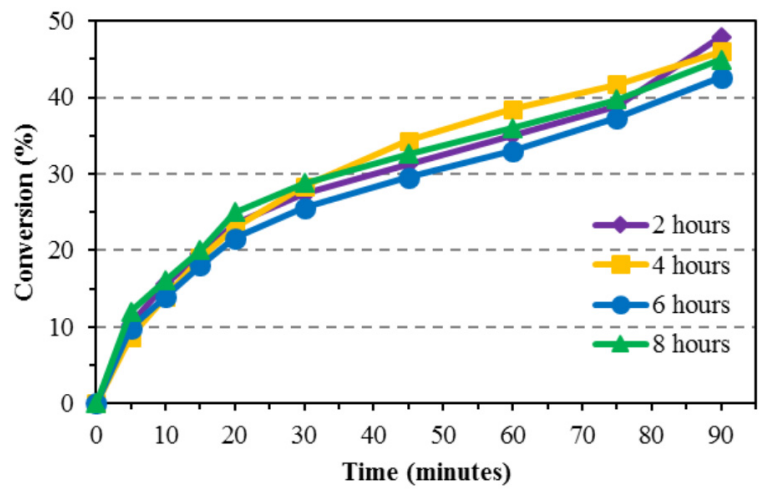

Figure 5. Eugenol conversion on sulfonated fly ash catalysts. 


\subsection{Conversion of Eugenol to Eugenyl Acetate}

To find out the performance of sulfuric-acidactivated fly ash catalyst, synthesis from eugenol to eugenol acetate is carried out by esterification of eugenol within clove oil and acetic acid. This reaction is operated at a temperature of $60{ }^{\circ} \mathrm{C}$. Conversion from eugenol to eugenyl acetate as function of time is shown on Figure 5.

The conversion from eugenol to eugenyl acetate with activated fly ash catalyst goes to show that all catalysts with different time preparation for calcination display almost the same performance. After the reaction has been carried out for 90 minutes, eugenol conversion was $43-48 \%$ completed. To have a higher level of conversion, a much longer time is needed for eugenol esterification. The performance of catalyst is comparable with the acidic zirconia and Amberlite ZAD-16 catalyst. Yadav and Yadav reported that conversion $30 \%$ were obtained by esterification of eugenol with benzoic acid over a solid super acidic modified zirconia catalyst at temperature of $80{ }^{\circ} \mathrm{C}$ for 90 minutes reaction [16]. High conversion at around 90\% was achieved when temperature was increased up to $110{ }^{\circ} \mathrm{C}$ for 240 minutes reaction. Using Amberlite XAD-16 reaction between eugenol and acetic anhydride to form eugenyl acetate achieved $85.0 \%$ and $98.6 \%$ conversion for reaction time 180 and 360 minutes, respectively and molar ratio 1:3 [17]. Other result [21] inform us that eugenyl acetate by enzymatic esterification of Novozym 435 as catalyst which come from the catalyst and the conversion of eugenyl acetate of $99.87 \%$.

An optimum condition was reached from eugenyl acetate at temperature of $60{ }^{\circ} \mathrm{C}$, the ratio molar of clove oils and acetic anhydride 1:5, and $10 \%$ of catalyst from the total enzymes for two hours reaction. A comprehensive investigation of various parameters effects such as temperature, reaction time, catalyst loading, and mole ratio of reactant should be taken account to develop the kinetic model.

\section{Conclusions}

In this work, fly ash based catalysts were prepared by impregnation different time with sulfuric acid and then calcined at $400{ }^{\circ} \mathrm{C}$ for transformation eugenol to eugenyl acetate. Impregnation and then calcination alter the adsorption volume of solid acid catalyst. Chemical and heat treatment of fly ash modify the fly ash composition and increase the pores size. The activated fly ash as acid solid catalyst for euge- nol esterification has exhibited the promising performance. However, various reaction parameters should be carried out to investigate completely in order to increase performance of fly ash activity for eugenol esterification.

\section{References}

[1] Yao, Z.T., Ji, X.S., Sarker, P.K., Tang, J.H., Ge, L.Q., Xia, M.S., Xi, Y.Q. (2015). A comprehensive review on the applications of coal fly ash. Earth-Science Rev., 141: 105-121.

[2] Ward, C.R., French, D., Jankowski, J., Dubikova, M., Li, Z., Riley, K.W. (2009). Element mobility from fresh and long-stored acidic fly ashes associated with an Australian power station. Int. J. Coal Geol., 80(3-4): 224236.

[3] Biernacki, J.J., Vazrala, A.K., Wayne Leimer, H. (2008). Sintering of a class F fly ash. Fuel, 87(6): 782-792.

[4] Alam, J., Akhtar, M.N. (2011). Fly ash utilization in different sectors in Indian scenario. Int. J. Emerg. Trends Eng. Dev., 1(1): 1-14.

[5] Ojha, K., Pradhan, N.C. (2001). Treated fly ash: A potential catalyst for catalytic cracking. Indian J. Eng. Mater. Sci., 8(2): 100-103.

[6] Mazumder, N.A., Rano, N.A., Sarmah, G. (2015). A green and efficient solid acid catalyst from coal fly ash for Fischer esterification reaction. J. Ind. Eng. Chem., 32: 211-217.

[7] Ho, W.W.S., Ng, H.K., Gan, S., Tan, S.H. (2014). Evaluation of palm oil mill fly ash supported calcium oxide as a heterogeneous base catalyst in biodiesel synthesis from crude palm oil. Energy Convers. Manag., 88: 1167-1178.

[8] Zeng, D., Liu, S., Gong, W., Qiu, J., Chen, H., Wang, G. (2014). A Brønsted solid acid synthesized from fly ash for vapor phase dehydration of methanol. Fuel, 119: 202-206.

[9] Srivastava, K., Devra, V., Rani, A. (2014). Fly ash supported vanadia catalyst: An efficient catalyst for vapor phase partial oxidation of toluene in a micro-reactor. Fuel Process. Technol., 121: 1-8.

[10] Akbay, E.O., Altiokka, M.R. (2011). Kinetics of esterification of acetic acid with n-amyl alcohol in the presence of Amberlyst-36. Appl. Catal. A Gen., 396(1-2): 14-19.

[11] Chen, Y., Cao, Y., Suo, Y., Zheng, G.P., Guan, X.X., Zheng, X.C. (2015). Mesoporous solid acid catalysts of 12-tungstosilicic acid anchored to SBA-15: Characterization and catalytic properties for esterification of oleic acid with methanol. J. Taiwan Inst. Chem. Eng., 51: 186-192. 
[12] Azudin, N.Y., Don, M.M., Shukor, S.R.A. (2013). Production and kinetics of isoamyl acetate from acetic anhydride using candida Antarctica lipase B in a solvent-free system. Chem. Eng. Trans., 32: 1057-1062.

[13] Osorio-Viana, W., Duque-Bernal, M., Fontalvo, J., Dobrosz-Gómez, I., Gómez-García, M. Á. (2013). Kinetic study on the catalytic esterification of acetic acid with isoamyl alcohol over Amberlite IR-120. Chem. Eng. Sci., 101: 755-763.

[14] Qiuyun, Z., Qiuyun, Z., Hu, L., Wenting, Q., Xiaofang, L., Yuping, Z., Wei, X., Song, Y. (2013). Solid Acid Used as Highly Efficient Catalyst for Esterification of Free Fatty Acids with Alcohols. China Petroleum Processing and Petrochemical Technology 15(1): 19-24.

[15] Patidar, P., Mahajani, S.M. (2012). Esterification of fusel oil using reactive distillation Part I: Reaction kinetics. Chem. Eng. J., 207208: 377-387.

[16] Yadav, G.D., Yadav, A.R. (2012). Insight into esterification of eugenol to eugenol benzoate using a solid super acidic modified zirconia catalyst UDCaT-5. Chem. Eng. J., 192: 146155.

[17] Laroque, D.A., Maria, R.A.L., Silva, J.A., Pereira, G.N. (2015). Synthesis of Eugenyl Acetate in Solvent-Free Acetylation: Process Optimization and Kinetic Evaluation. J. Chem. Eng. Process Technol., 6(4): 4-11.
[18] Lerin, L.A., Catani, M., Oliveira, D., Massi, A., Bortolini, O., Cavazzini, A., Giovannini, P.P. (2015). Continuous ion-exchange resin catalysed esterification of eugenol for the optimized production of eugenyl acetate using a packed bed microreactor. RSC Adv., 5: 7689876903.

[19] Khatri, C., Mishra, M.K., Rani, A. (2010). Synthesis and characterization of fly ash supported sulfated zirconia catalyst for benzylation reactions. Fuel Process. Technol., 91(10): 1288-1295.

[20] Thirunarayanan, G., Mayavel, P., Thirumurthy, K. (2012). Fly-ash: $\mathrm{H}_{2} \mathrm{SO}_{4}$ catalyzed solvent free efficient synthesis of some aryl chalcones under microwave irradiation. Spectrochim. Acta Part A Mol. Biomol. Spectrosc., 91: 18-22.

[21] Vanin, A.B., Orlando, T., Piazza, S.P., Puton, B.M.S., Cansian, R.L., Oliveira, D., Paroul, N. (2014). Antimicrobial and Antioxidant Activities of Clove Essential Oil and Eugenyl Acetate Produced by Enzymatic Esterification. Appl. Biochem. Biotechnol., 174(4): 12861298.

Selected and Revised Papers from The $3^{\text {rd }}$ International Conference on Chemical and Material Engineering (ICCME) 2018 (http://iccme2018.undip.ac.id) (Diponegoro University, by $19^{\text {th }}$-20 ${ }^{\text {th }}$ September 2018) after Peer-reviewed by Scientific Committee of ICCME 2018 and Peer-Reviewers of Bulletin of Chemical Reaction Engineering \& Catalysis 